\title{
Psychiatric and other contributing factors in homicide-suicide cases, from northern Gauteng, South Africa over a six-year period
}

Carla Kotzé, Nadira Khamker, Gian Lippi, Kalai Naidu, J Mosidi Pooe, Funeka B Sokudela and J Louw Roos

Weskoppies Psychiatric Hospital / Department of Psychiatry, School of Medicine, Faculty of Health Science, University of Pretoria, South Africa

\begin{abstract}
Homicide committed by a person who subsequently commits suicide within one week of the homicide, is a relatively rare event. The current study used an explanatory sequential design, including psychological autopsies, to identify psychiatric and other contributing factors in 35 homicide-suicide cases in northern Gauteng Province, South Africa. This research highlighted the complex multifactorial nature of these events. Identification of high-risk individuals and delineation of contributing factors is important. Early recognition and effective treatment of psychiatric illness, particularly depression and substance use problems, in people experiencing relationship issues (with pending/recent separations) and financial stressors, is an essential component in the prevention of homicide-suicide incidents. Evaluations should always include direct questioning about suicidal and homicidal ideations. Mental health practitioners have a definite role to play in offering comfort, support and treatment to all those who remain behind after these devastating events. Urgent attention needs to be given to the availability of support and treatment for investigating police officers and surviving family and friends.
\end{abstract}


Keywords: Homicide-suicide; psychiatric factors; contributing factors

\section{Introduction}

"Death, of course, is a refuge. It's where you go when a new name, or a mask or cape, can no longer hide you from yourself. It's where you run to when none of the principalities of your conscience will grant you asylum.” (Cleave, 2008, p. 22)

Homicide-suicide (HS) is a relatively rare event that has a far-reaching impact, affecting surviving family, friends, colleagues, witnesses and investigators, and which constitutes an emerging public health problem. HS has been defined as homicide committed by a person who subsequently commits suicide within one week of the homicide (Marzuk, Tardif \& Hirsch, 1992). In most cases the subsequent suicide occurs within a 24-hour period (Knoll, 2016).

The incidence of HS varies around the world, but some studies have shown a relatively consistent global incidence averaging 0.2 - 0.3 per 100,000 persons (Coid, 1983; Eliason, 2009; Marzuk et al., 1992). Rates in the United States range from 0.134 to 0.55 per 100,000 (Bossarte, Simon \& Barker, 2006). Research in two different regions of South Africa reflects a higher incidence than the international average. The annual incidence of HS in the Pretoria region of South Africa’s Gauteng Province from January 1997 to October 2001 averaged one per 100,000 (Jena, Mountany \& Muller, 2009). This is from the same region as the present study. In Durban, in South Africa's KwaZulu-Natal Province, the incidence was 0.89 per 100,000 for the years 2000 to 2001 (Roberts, Wassenaar, Canetto \& Pillay, 2009).

Most research suggests that perpetrators of HS differ from those of typical perpetrators of murder or those who commit suicide in terms of socio-demographic characteristics, and that they are usually older and more likely to be married or recently separated. HS has unique characteristics that distinguish it from homicide only or suicide 
only, and seems to be more likely to be precipitated by interpersonal crises than suicide only (Knoll, 2016).

Apart from those pertaining to incidence, findings in the South African studies are generally similar to those found globally in that the majority of HS cases are committed by middle-aged men, with most victims being female and the perpetrator's younger intimate partner of the same race. The most frequent apparent reason for murder is the breakdown of an intimate relationship. Shooting is the commonest method used (Eliason, 2009). Alcohol use is associated with perpetrators and victims at the time of the HS, with a preponderance in the former (Chan, Beh \& Broadhurst, 2003; Felthous \& Hempel, 1995; Lecomte \& Fornes, 1998; Milroy, Dratsas \& Ranson, 1997; Shiferaw, Burkhardt, Lardi, Mangin \& La Harpe, 2010).

The available literature often focuses on the epidemiology and socio-demographics of HS with a relative paucity of information related to psychiatric factors. A review on mental illness in HS found that depression was the most frequent psychiatric disorder reported (in about $39 \%$ of the offenders in the 20 studies that assessed depressive disorders), followed by substance abuse (about 20\% of the offenders in 10 studies) and psychosis (about $17 \%$ of the offenders in 11 studies) (Roma et al., 2012). Rosenbaum and Bennett (1986) strongly suggest that depressed patients most at risk for homicide-suicide are those suffering from one of the following: a personality disorder or traits of a personality disorder; a history of child abuse; a history of alcohol and substance abuse; suicidal behaviour; or depression precipitated by sexual infidelity (real or imagined). While depression appears to be one of the most common psychiatric disorders associated with HS, previous studies typically lack detailed information on the dynamics underlying the event, the motives involved and the role of other precipitating factors (Roma et al., 2012). For this reason, several researchers have called for further studies, 
including studies that evaluate survivors of these acts and/or that make use of psychological autopsy methods (Cohen, Llorente \& Eisdorfer, 1998; Liem, 2010; Roos \& Bodemer, 1989).

To date, in only two other studies were family members interviewed following the psychological autopsy approach (Knoll \& Hatters-Friedman, 2015; Rosenbaum, 1990). Shneidman (1969) coined the term 'psychological autopsy' to describe a thorough retrospective investigation to obtain information about the intention of the deceased. Individuals who know the deceased's actions, behavior and character well enough to report on them are interviewed to obtain the relevant information (Shneidman, 1981).

Using the psychological autopsy method, the data from HS cases became more complete, making conclusions more accurate. Psychological autopsies are superior to mere record review because they are more comprehensive and more likely to capture psychological and contextual circumstances preceding the HS (Conner et al., 2011). Data are synthesized from multiple sources, resulting in an in-depth understanding of personality, behaviour and motives. Unique and critical individual information may not be present in police or coroner records, which do not typically focus on such data (Knoll \& Hatters-Friedman, 2015).

From the available literature, it is clear that individual variables are not sufficient to explain the HS phenomenon; psychopathology, interpersonal dynamics, stressors and other community factors are implicated. Social support; help from health-care professionals, family and friends; support in seeking domestic violence protection; and assistance with conflict management and resolution are essential (Malphurs, Eisdorder \& Cohen, 2001). If prevention and intervention strategies are not sensitive to the understanding and worldview of the patients, then these strategies may not be effective, or may even fail completely (Bell, Dominica \& McBride, 2010). Socioeconomic data, medical and psychiatric evaluations, information about cultural variables, information about the possession of firearms, and data 
on previous episodes of violence, have been shown to aid the understanding and prevention of this phenomenon. (Goranson, Boehnlein \& Drummond, 2012).

Although most forensic psychiatrists do not routinely perform psychological autopsies, there is a growing need for such professional involvement, which includes cooperation and interaction with other forensic scientists. Moreover, some of the basic principles of forensic psychiatry can easily be applied to psychological autopsy evaluations (Botello, Weinberger \& Gross, 2003). A pilot study done at Weskoppies Hospital / University of Pretoria evaluated nine cases where perpetrators of homicide survived a subsequent suicide attempt. It was found that psychosocial stressors and failure of coping mechanisms during periods of strife within an intimate relationship were prominent and should be a focus of future research. It also suggested that separation should possibly be investigated as an independent factor that promotes interpersonal difficulty associated with HS (Sussman \& Kotze, 2013). The current study took previous recommendations into account and aims to identify psychiatric and other factors contributing to HS.

\section{Methods}

The Head of Forensic Medicine, University of Pretoria, approached the Department of Psychiatry at the university to research the driving force behind HS incidents. The impact on survivors and staff members investigating these cases sparked this research.

\section{Ethical considerations}

As this study is of an extremely sensitive nature, permission was obtained initially from the Chief Executive Officer: Forensic Pathology Services and the Provincial Commissioner, South African Police Service (SAPS) Gauteng, with final ethical approval from the Faculty of Health Sciences Research Ethics Committee, University of Pretoria. Prerequisites to obtain permission were that the SAPS had to be the first point of contact and 
that all participants in the psychological autopsy, including investigating officers and family members or friends of the deceased, should be offered psychiatric treatment or counselling.

\section{Sampling}

Purposeful sampling was used and all cases of HS (evidence of self-inflicted death after committing a homicide) identified by the Department of Forensic Medicine, University of Pretoria, from 1 January 2009 until 31 December 2014 (6-year period) were included. This department is responsible for the routine medico-legal investigation of unnatural deaths in the greater Tshwane metropolitan area and approximately 3,000 such deaths are investigated annually. There is no unique coding system for HS cases and a designated forensic pathologist had to personally identify specific cases. This is a time-consuming process and contact information in older files was not always reliable, because people had moved or telephone numbers had changed. For these reasons, it was decided not to include cases from before 1 January 2009. A total of 35 cases were identified for inclusion.

\section{Procedures}

This was an explanatory sequential-design study where the collection of quantitative data was followed by the collection of qualitative data to investigate psychiatric and other contributing factors in HS cases in northern Gauteng Province, South Africa. After identification of the HS cases by the Department of Forensic Medicine, the principal investigator captured the following quantitative data from the Forensic Medicine files: SAPS details (including investigating officer name, contact number and case numbers); sociodemographic information about the HS perpetrators and victims (age, gender, home address. marital status, occupation and the nature of the relationship between victim and perpetrator); post-mortem and laboratory details (date of death, place of death, method / cause of death, other injuries noted, toxicology results e.g. alcohol levels); suicide and other relevant affidavit notes (e.g. witness statements); next of kin name and contact numbers. 
The research team consisted of nine psychiatrists from the Department of Psychiatry at the University of Pretoria who were prepared to participate in this study. All the psychiatrists were involved in forensic psychiatric practice at Weskoppies Tertiary Psychiatric Hospital with experience in this field ranging from five years to 34 years. The researchers were grouped into teams of two and HS cases for further qualitative investigation were allocated in a sequential manner with the purpose of exploring the findings in more depth. Interviews were conducted with all SAPS investigating officers and family or friends of the HS victims who could be contacted with the available information, were older than 18-years of age, were able to give informed consent and were willing to participate in the research.

In 26 of the total of 35 cases further qualitative data was obtained. The SAPS provided valuable additional information in eight cases, and in the other 18 cases, information was obtained from interviews with the perpetrator or victim's next of kin. In 9 cases both the perpetrator and the victim's next of kin were interviewed, in 5 cases only the perpetrators' next of kin were interviewed and in 4 cases only the victim's next of kin.

In the qualitative data-collection phase the researchers established research pathways after lengthy discussions and deliberations. The qualitative research guidelines included: Contacting the SAPS investigating officer to obtain statements, contact numbers of next of kin and other informants; Identifying a place of interview and obtaining informed consent; The use of audio recordings and transcriptions; The use of field notes (researchers' own written notes and summaries); and Referral of informants with mental health problems for evaluation and treatment.

For each case, the SAPS investigating officer involved, or another designated officer, was the first point of contact for the researchers. The SAPS contact person was informed about the research and asked to contact family members of the deceased to discuss the research proposal and request their permission for the researchers to contact them. The 
contact details used were those obtained from the Forensic Medicine files or available in the police docket, and were mostly for family members who identified the deceased or were interviewed by the police following the HS.

The researchers then contacted people willing to participate to explain the nature of the research, as described in the informed consent, and arrange appointments to meet. The most suitable venue for the interview was discussed with the interviewee. It was preferable that the interview be done in an environment that was familiar to the interviewee. After taking these measures into account, the interview could also be scheduled at Weskoppies Psychiatric Hospital. Telephone interviews were done with participants who resided too far away for a face-to-face interview to be feasible. After these interviews psychiatric care and treatment was offered and arranged for research participants with psychiatric, social or other emotional problems.

The methods employed in this study were semi-structured interviews and additional sources of information included news reports, suicide notes and letters written to family members. The two psychiatrists allocated to each case were responsible for the qualitative data collection for that case. In the qualitative methodological account, the aim was to elucidate the significance and meaning people attach to social situations. (Schurink, De Jongh van Arkel \& Roos, 1992).

The researchers followed semi-structured guidelines for the interviews as set out in the Shneidman (1969) criteria for the performance of psychological autopsies and this includes: basic identifying information; specific details of the death; outline of the perpetrator and victim's previous history (e.g. suicide attempts / intent, psychiatric treatment, personality characteristics, recent stressors, alcohol / drug use, changes in routine before death); family psychiatric history; quality of the perpetrator-victim relationship and other interpersonal relationships; reaction of informants to the death. (Scott, Swartz \& Warburton, 2006). This 
methodology involves a qualitative approach that provides loose guidelines for the researcher to follow, described as a "mixture of conversation, interview, emotional support, general questions, and a good deal of listening" (Scott, Swartz \& Warburton, 2006, p813). As part of the psychological autopsy, the researcher attempts to reconstruct the lifestyle of the victim, paying particular attention to the period of time immediately preceding the death. It has also been stressed that these criteria should not serve as a rigid structure, but rather as a set of general guidelines (Knoll \& Hatters-Friedman, 2015).

The guidelines for the interviews were followed, but the nature of the semi-structured interviews varied considerably according to the nature of the relationship between the interviewee and the deceased. The nature of this relationship greatly influenced the sensitivity of the interview and the information that could be provided by the informant.

It is apparent from the natural history that the following decisions and actions were relatively typical: After informed consent was given and the informant was assured of the confidentiality of the information, special attention was devoted to placing subjects at ease; For practical reasons, it was not possible to conduct more than one interview with each of the subjects; The length of the interviews varied, but were seldom less than 20 minutes in duration; An attempt was made throughout to make audio-recordings of the interviews, to have two psychiatrists present per interview and to keep field notes; In cases where language barriers existed, family members and/or the second research psychiatrist acted as interpreters; In light of the sensitive nature of the research phenomenon, a decision was made that the team members, in addition to their assigned role as researchers, would also have to fulfil a supportive role.

It is important to note that during the psychological autopsy evaluation, the forensic psychiatric/psychological examiner may contact people who are still in the grieving process. The primary purpose of the psychological autopsy is not therapeutic, but it is to gather 
information, in a sensitive manner, to determine the deceased's mental capacity to form the intent to commit suicide. It is common policy to suggest to the family members / significant others that they seek outside counselling to help them deal with the grieving process. However, the survivors often state spontaneously that the psychological autopsy was of therapeutic value to them as it allowed them to vent their feelings about the decedent's death and talk about the decedent's life (Botello et al., 2003).

\section{Data analysis}

It is necessary to note that analysis of such data cannot really be separated from the steps/decisions taken during the process of the qualitative research. Although analysis and interpretation of the data (transcriptions of interviews, field notes, diaries, official SAPS documents, newspaper articles, etc.) were mainly done at the end of the investigation, provisional analysis and interpretation occurred throughout the research process.

The data collection and analysis was an ongoing, recursive and dynamic process that occurred throughout the research investigation. Triangulation, using multiple sources of data with observations at different times and different places, as well as interview data collected from people with different perspectives was used to ensure validity of the data. Investigator triangulation was also used, with multiple investigators collecting and analysing the data.

After the two research psychiatrists submitted their collected data on a specific HS case, the case study was discussed at a meeting with the other researchers. In addition, the principal investigator and another research psychiatrist then reread the data. During this process, psychiatric diagnosis was verified, classifications were assigned, emerging themes were identified and insights were highlighted. The HS cases were classified into the major patterns proposed by Knoll (2016). This classification involves a 2-part label. The first part is based on perpetrator's relationship to the victim and the second part specifies the motive of the perpetrator. When psychological autopsies are used to investigate HS cases, a more 
accurate determination of motive can be made improving the reliability of these classifications (Knoll, 2016). In our study multiple investigators checked the classification independently.

A total of 18 meetings were arranged during the research period. The data were interpreted inductively and a hypothesis was formulated from the data obtained. We examined the data for general themes, concepts or patterns of interaction that occur fairly commonly, or that can serve as behavioural norms. We tried to determine why such generalities occurred. We were also alert to deviations from these generalities/norms and to possible reasons for these. There are no fixed rules for identifying themes and norms.

To obtain these objectives the following guidelines were used: Read and reread the data; Remain on the trail of themes, speculations, interpretations and ideas; Watch for developing themes; Construct typologies (typologies or classification schemes can be useful aids in identifying the theories and concepts and eventually developing a theory); Develop concepts and theoretical propositions; Read the literature. Once everything is ready, it is essential to take cognizance of the existing literature and of those theoretical frameworks that are pertinent to the investigation (Schurink et al, 1992).

While not all steps mentioned above were used in the present investigation, these guidelines were used as a broad framework for analysing the data. This process was followed until the emerging findings were saturated.

\section{Results}

There were a total of 35 cases identified by the Department of Forensic Medicine during the specified time period. The total number of victims in these 35 HS cases amounted to 43 homicides. Additional qualitative information could be obtained for 26 of the 35 cases. Both quantitative and qualitative findings are given below. 


\section{Homicide-suicide details}

The mean age of the perpetrators was 38.6 years (ranging from 24 to 73 ). In eight of the cases, the perpetrators' employment required them to carry firearms (e.g., SAPS / security services) and seven of the perpetrators were unemployed.

The most common method of homicide was shooting, used in 25 of the 43 homicide cases $(58.1 \%)$. Other homicide methods used included stabbing in seven cases (16.3\%), blunt force trauma in five cases $(11.6 \%)$, strangulation in four cases $(9.3 \%)$, and poisoning in two cases $(4.7 \%)$. Shooting was also the most common method of committing suicide and was used in 20 cases $(57.1 \%)$. Other suicide methods included 10 cases of hanging (28.6\%), two cases of poisoning (5.7\%), and one case each (2.9\%) of stabbing, gassing and jumping in front of a train. The HS classifications that we found in our study are summarized in Table 1 and included: Intimate-possessive, Filicide-suicide, Familicide-suicide, Extrafamilial homicide-suicide, and Familial-psychotic (Knoll, 2016).

\begin{tabular}{|l|l|l|l|l|l|}
\hline \multicolumn{2}{|l|}{ Table 1: Summary of types of homicide and perpetrators' socio-demographic factors } \\
Classification of type of & Total & \% of Total & Male & Female & Armed \\
homicide & & & & & employment \\
\hline C1: Intimate-possessive & 22 & 62.8 & 22 & 0 & 7 \\
\hline C2: Filicide-suicide & 7 & 20 & 4 & 3 & 1 \\
\hline C3: Familicide-suicide & 4 & 11.4 & 4 & 0 & \\
\hline C4: Extra-familial HS & 1 & 2.9 & 1 & 0 & \\
\hline C5: Familial-psychotic & 1 & 2.9 & 1 & 0 & \\
\hline
\end{tabular}

In our study, there were only three female perpetrators, and in all three cases, they killed their children. The one extrafamilial case in our study, where the victim was not a partner or family member, followed the pattern that has been described as adversarial HS and 
involved a disgruntled individual (Large, Smith \& Nielssen, 2009). In five cases, there were multiple victims. The mean age for the victims was 26.0 years, with an age range of five months to 72 years. Of the total number of victims, nine were male and 34 female.

\section{Psychiatric factors}

A psychiatric diagnosis was made in $15(42.9 \%)$ of the total 35 cases, or $58 \%$ of the 26 cases where psychological autopsies were performed.

A mood disorder-related diagnosis was made in nine (34.6\%) of the perpetrators. The specific mood disorder diagnoses included major depressive disorder and adjustment disorder with depressed mood. In three of the cases of adjustment disorder with depressed mood, the diagnosis was related to a diagnosis of HIV. According to the available information, only two of the perpetrators were receiving antidepressant treatment at the time of the incident. Comorbid diagnoses were common with the mood disorders and included alcohol and substance use disorders, and personality disorders/traits. We identified six individuals with traits suggestive of different types of personality disorders (23.1\%). Seven (26.9\%) of the perpetrators had a substance- or alcohol-related disorder diagnosis.

In the present study, only one perpetrator was diagnosed with a psychotic disorder, specifically Othello Syndrome or delusional jealously. Refer to Table 2 for a summary of the psychiatric diagnoses made. 


\begin{tabular}{|c|c|c|c|}
\hline $\begin{array}{l}\text { Classific } \\
\text { ation }\end{array}$ & Primary psychiatric diagnosis & $\begin{array}{l}\text { Substance use } \\
\text { disorders }\end{array}$ & $\begin{array}{l}\text { Personality disorders } \\
\text { (PD) }\end{array}$ \\
\hline $\mathrm{C} 1$ & $\begin{array}{l}\text { Adjustment disorder, with depressed } \\
\text { mood (recent HIV diagnosis) }\end{array}$ & $\begin{array}{l}\text { Alcohol/cannabis } \\
\text { use disorder }\end{array}$ & \\
\hline $\mathrm{C} 2$ & $\begin{array}{l}\text { Major depressive disorder, with post- } \\
\text { partum onset }\end{array}$ & & \\
\hline $\mathrm{C} 1$ & $\begin{array}{l}\text { Adjustment disorder, with depressed } \\
\text { mood (recent HIV diagnosis) }\end{array}$ & & \\
\hline $\mathrm{C} 5$ & $\begin{array}{l}\text { Delusional disorder } \\
\text { Depressive disorder } \\
\text { Post-traumatic stress disorder }\end{array}$ & $\begin{array}{l}\text { Opioid use } \\
\text { disorder }\end{array}$ & \\
\hline $\mathrm{C} 3$ & Major depressive disorder & $\begin{array}{l}\text { Alcohol use } \\
\text { disorder }\end{array}$ & $\begin{array}{l}\text { Anti-social and } \\
\text { narcissistic traits }\end{array}$ \\
\hline $\mathrm{C} 2$ & $\begin{array}{l}\text { Adjustment disorder, with depressed } \\
\text { mood }\end{array}$ & & \\
\hline $\mathrm{C} 1$ & & $\begin{array}{l}\text { Alcohol use } \\
\text { disorder }\end{array}$ & $\begin{array}{l}\text { Borderline/dependent } \\
\text { traits }\end{array}$ \\
\hline $\mathrm{C} 3$ & & & Anti-social PD \\
\hline $\mathrm{C} 1$ & Major depressive disorder & $\begin{array}{l}\text { Alcohol use } \\
\text { disorder }\end{array}$ & \\
\hline $\mathrm{C} 1$ & & $\begin{array}{l}\text { Alcohol use } \\
\text { disorder }\end{array}$ & $\begin{array}{l}\text { Obsessive- } \\
\text { compulsive/dependent } \\
\text { traits }\end{array}$ \\
\hline $\mathrm{C} 3$ & & $\begin{array}{l}\text { Alcohol use } \\
\text { disorder }\end{array}$ & Borderline PD \\
\hline $\mathrm{C} 1$ & $\begin{array}{l}\text { Adjustment disorder, with depressed } \\
\text { mood (HIV-related) }\end{array}$ & & Anti-social PD \\
\hline $\mathrm{C} 1$ & & $\begin{array}{l}\text { Alcohol use } \\
\text { disorder }\end{array}$ & \\
\hline $\mathrm{C} 1$ & Major depressive disorder & & \\
\hline $\mathrm{C} 1$ & Major depressive disorder & & \\
\hline
\end{tabular}

C1: Intimate-Possessive; C2: Filicide; C3: Familicide; C5: Familial-psychotic 


\section{Psychosocial and other factors}

In the available literature, it has been suggested that the identification of other variables associated with violence should be included in future research. Other aspects enquired about in the current study included relationship problems, infidelity, recent or pending separation, domestic violence, financial/work-related stressors, and physical illness, and are summarized in Table 3. Evidence of planning was also enquired about and was found to be present in $12(46.1 \%)$ cases. These included acts such as the purchase of a firearm/poison, leaving letters/notes, doing internet searches for methods of killing, and telling people about intentions or making threats. Of the 43 victims five (11.6\%) were in possession of protection orders prior to the HS incident (Domestic Violence Act 116, 1998).

\begin{tabular}{|l|l|l|}
\hline \multicolumn{2}{|l|}{ Table 3: Summary of other psychosocial variables associated with homicide-suicide } \\
\hline Variable & Total out of 26 & $\%$ \\
\hline Relationship problems & 24 & $92.3 \%$ \\
\hline Infidelity (real/perceived) & 13 & $50 \%$ \\
\hline Financial/work stressors & 18 & $69.2 \%$ \\
\hline Recent/pending separation & 15 & $57.7 \%$ \\
\hline Domestic violence & 8 & $30.8 \%$ \\
\hline Physical illness & 3 & $11.5 \%$ \\
\hline
\end{tabular}

Of all the family members interviewed, only four reported that they received some form of professional support, counselling or treatment after the HS. All the people that were interviewed were offered psychiatric/psychological treatment as indicated. Most people declined the offer, but referrals were arranged in four cases. 
SAPS members indicated that counselling services are made available to them, but that they seldom make use of the facility. None of the SAPS investigators accepted offers for referrals for psychiatric assessment and treatment.

\section{Discussion}

The motivation for suicide is determined by a set of complex dynamics, and HS is even more bewildering (Bell et al., 2010). These events are multifactorial in nature and motivations are very complex.

In a recent editorial, it was stated that perhaps it is finally time to acknowledge that rare events such as suicide, as much as we may wish to prevent them, are impossible to predict with a degree of accuracy that is clinically meaningful (Mulder, Newton-Howes \& Coid, 2016). The same may apply to HS incidents, although it may be possible to identify risk factors associated with HS incidents. As was shown in the present study and in previous research, precipitating factors can be delineated that might assist in the reduction of the number of incidents (Flynn, Gask, Appleby \& Shaw, 2016). Another study has shown that about three out of ten HS cases might have been prevented if intervention had taken place for suicide or homicide-suicide threats, or if the perpetrator had received treatment for alcohol use problems (Saleva, Putkonen, Kiviruusu \& Lönnqvist, 2006).

In the present study, personality disorder or traits of personality disorders and substance use disorders in depressed patients played a prominent role. In five of the nine perpetrators diagnosed with a mood disorder, sexual infidelity was implicated. We also found that the breakdown of an intimate relationship, with a recent or pending separation, was the most common apparent contributing factor to HS (Felthous \& Hempel, 1995; Flynn et al., 2016). The personality traits identified were varied and, as was the case in a previous study, 
we could not identify a specific personality trait as a risk factor (Knoll \& Hatter-Friedman, 2015).

The one perpetrator who was diagnosed with Othello Syndrome had comorbid psychiatric diagnoses, including a depressive disorder, post-traumatic stress disorder, and opioid use disorder. Othello Syndrome is a psychiatric condition in which the degree of jealousy and/or belief of infidelity of one's spouse reach delusional intensity (Enoch and Trethowan, 1979). Othello syndrome can be in part subsumed in the diagnostic nomenclature set forth by DSM-5 under the diagnosis of delusional disorder, jealous type (American Psychiatric Association, 2013). The DSM-5 category of delusional disorder, jealous type covers only a portion of individuals suffering from Othello syndrome. The Othello syndrome may also be found as part of the symptom complex of other functional psychoses, such as schizophrenia or mood disorders with psychotic features (Enoch et al., 1979, Shepherd, 1961). Organic factors have been implicated as the casual agent that the more accurate diagnosis is organic delusional disorder (Cummings, 1985). From the aforementioned Othello syndrome is not seen as a distinct nosological entity.

In the present study, the perpetrator's psychotic disorder may have been linked to his opioid use disorder. The frequently observed co-occurrence of alcohol use disorders in Othello Syndrome patients has suggested a possible link between the two conditions. (Todd \& Dewhurst, 1955; Shrestha, Rees, Rix, Hore \& Faragher, 1985). Othello syndrome patients often harbour hostility towards others, secondary to the delusional jealousy (Leong et al, 1994). Such hostility may escalate to serious physical violence, including homicide, as in the case of the perpetrator with Othello Syndrome (Shepherd, 1961).

The Domestic Violence Act (1998) in South Africa includes the regulation of protection orders as a means to control domestic violence and if a protection order is in place it could reflect on the seriousness of the threats of violence. In 2015 Govender made the 
conclusions that the SAPS response to allegations of domestic violence is unprofessional and ineffective. It was reported that this often results in under reporting of domestic violence crimes. Patriarchal norms still dominate family relationships, giving rise to domestic violence and recidivists commit many of the domestic violence crimes. The SAPS should act more decisively and consistently to move towards dealing with the perpetrators of domestic violence (Govender, 2015). It was reported that in 2009 approximately one in 20 of the women killed by their intimate partners in South Africa were in possession of a protection order (Vetten, 2017). In the present study five of the victims had protection orders against the perpetrators. It was also found that despite the presence of relationship problems and even protection orders, family and friends usually find the HS completely unexpected, as reflected in these statements made by participants: "I saw her almost every day and never imagined that something like this could happen," and, "We can't accept this. We were not expecting such a thing."

The effects of HS were also evident in family and friends who struggled to make sense of the driving forces behind such an act. The statements they made included: "It was pure evil, pure selfishness. We are so confused."; "I don't accept that being depressed is sufficient cause to do what he did. I think a lot of it was jealousy."; "The way he did it, that says to me that there was some kind of hatred there."; "It is so unreal that he died in this way. It is very difficult for us."; "He wanted her to be in his sight all the time. He was very jealous and possessive. He was obsessed with her."

These cases also adversely affected some of the members of the SAPS who were investigating them. In some instances, they knew the people involved from the community, or as colleagues, making it even more traumatic for them. Some statements by them were: "I went through hell and do not want to be reminded of it. I do not want to talk about this," and, "It is one of those cases that sticks with you. It kept on coming back". 
A study done on family murders in South Africa concluded that mood disorders with suicide ideations constitute an important psychiatric factor in the aetiology of family murder. (Roos, Beyers \& Visser, 1992). This psychiatric factor in interplay with certain personality traits and stressors sets the scene for a family murder to take place. The results of the family murder study indicated that it is very important for a psychiatrist treating a depressed patient to enquire not only about suicidal thoughts, but also to explore homicidal thoughts and intentions directed towards close relatives, particularly if there are vulnerable potential victims, such as young children (Olivier et al., 1991; Roos, Beyers \& Visser,1992).

It must also be kept in mind that, as reflected in our findings and the available literature, men are consistently shown as the most frequent perpetrators, who mostly kill their female partners, or in a few cases their whole family, before killing themselves. Young children are the second most frequent homicide victims (Eliason, 2009; Flynn et al., 2016, Lecomte \& Fornes, 1998).

The most common methods used to commit homicide in this study, as well as the finding that the perpetrators mostly use the same method to commit suicide, were consistent with the available literature (Large et al., 2009; Saint-Martin, Bouyssy \& O’Byrne, 2006). Shooting is the most frequently used method of both homicide and suicide in most Western countries (almost 90\% of all cases in the United States) (Eliason, 2009). In China and Japan, the most frequent methods used are strangulation/hanging and stabbing (Chan et al., 2003; Satoh \& Osawa, 2016). Cross-national differences in the availability of firearms may explain international variations of homicide-suicide rates and patterns, and restricted access to guns may be one of the most potent ways to prevent HS and other lethal intentional violence (Liem, Barber, Markwalder, Killias \& Nieuwbeerta, 2011; Malphurs et al., 2001).

Qualitative research is an intricate and complex process during which several decisions and steps are typically taken simultaneously. A full account of this multifaceted 
enterprise was not possible in the method section. While many factors have obviously threatened the results of the current study, the researchers feel sure that at least the major observer effects were sufficiently covered and that the data collected did in fact have a high degree of validity. While the present study cannot offer an exhaustive description of the phenomenon of homicide-suicide as it manifests in the Gauteng region of South Africa, it does represent a relatively extensive study of 35 authentic cases of homicide-suicide.

\section{Clinical implications}

In the management of patients with mood disorders, primary care physicians, psychiatrists and psychologists must not only enquire about suicidal ideation, they must also explore homicidal thoughts and intentions directed towards close relatives, particularly if there are vulnerable potential victims, such as young children. Physicians cannot be expected to prevent homicide-suicide directly, but they can reduce risk generally if they treat depression and recognize the risks associated with domestic violence (Flynn et al., 2016).

Psychotic disorders did not feature prominently among psychiatric diagnostic entities. Physicians must be aware that delusional jealousy (Othello Syndrome), often raises significant forensic issues, particularly dangerousness. In cases of Othello Syndrome in which organic factors (including substance use disorders) played a significant role, physicians must be even more aware of dangerousness directed towards the person involved in the delusional jealousy (Leong et al., 1994).

According to the Domestic Violence Act, No 116 of 1998, victims of domestic violence have the right to apply for a protection order from the SA courts. Physicians should be aware that in certain cases where protection orders have been granted, it may create a false sense of security. The present study showed that the perpetrators committed suicide-homicide in spite of protection orders being in place. While the Act emphasizes the importance of affording victims of domestic violence maximum protection, it fails to safeguard the state 
against litigation resulting from the unlawful conduct of the police. This lacuna can be avoided if police are properly trained in such matters, particularly when to detain. It is, therefore, doubtful whether the Act is the solution to domestic violence in South Africa (Sibisi, 2016).

We will never be able to prevent all cases of homicide-suicide. There will always be family, friends and other contacts of the perpetrators who may be traumatized after these events. All members of the multi-professional psychiatric team have a role to play in the initial management and rehabilitation of these people. Members of police services and emergency personnel must also be kept in mind. The psychiatric management of members of the SAPS does not seem to be working, and other measures should be put in place.

\section{Limitations}

The study was conducted on a small, regional sample that limits the extension of the results to other areas. That being said, most of the findings, including the perpetrator and victim profiles and HS methods were in keeping with those of other studies that included national data and used other research methods. (Chan, Beh \& Broadhurst, 2003; Felthous \& Hempel, 1995; Lecomte \& Fornes, 1998; Milroy, Dratsas \& Ranson, 1997; Shiferaw, Burkhardt, Lardi, Mangin \& La Harpe, 2010). Retrospectively, post-mortem analysis can introduce bias, but because the parties involved with the HS are deceased, information is limited and difficult to obtain. Triangulation was used to limit the introduction of bias and to ensure the validity of the data. Only psychiatrists with at least five years' experience in forensic psychiatric assessments made the psychiatric diagnoses in this study, but independent reviews of the cases and additional independent interviews that could have ensured better reliability were not done.

Psychological autopsies could not be performed in all the HS cases and the number of psychiatric diagnoses made may have been higher if collateral information could have been 
obtained in all cases. Some reasons why psychological autopsies could not be performed in all the cases were difficulties in contacting the SAPS investigating officers involved with certain cases (because of transfers, etc.) and emotional difficulties in survivors and investigating officers that made them reluctant to participate in the research. Even in cases where additional information was obtained through interviews, it remained difficult to determine a perpetrator's mental state at the time of the HS incident. For these reasons, no causal relationship could be established and at most we could identify risk factors and other contributing/precipitating factors that play roles in HS.

As the accuracy of determination of motive in the Knoll (2016) classification of HS may remain problematic in certain cases, this may be seen as a limitation in the study.

\section{Conclusions}

Although it is unrealistic to expect mental health and general health care practitioners to prevent $\mathrm{HS}$, the identification of precipitating factors and high-risk individuals can assist in reducing the number of incidents. Our study found that early recognition and effective treatment of psychiatric illness, particularly depression and substance use problems, in people experiencing relationship issues (with pending/recent separations) and financial stressors, should be an essential component in the prevention of HS incidents. Improvements in service delivery will have to focus on direct questioning about these issues, as well as suicidal and homicidal ideations.

The establishment of a nation-wide system to collect data, with a special register of such cases, will assist future research into this phenomenon. The other area that needs urgent attention and where service delivery will have to be improved on a national basis is the availability of support and treatment for SAPS investigators and surviving family and friends. 
Their overall well-being should be addressed through meaningful social support and effective medical care.

It will never be possible to prevent all HS cases, but medical, mental health and social service professionals have a definite role to play in offering comfort, support and treatment to all those who remain behind after these events.

\section{Acknowledgments}

We would like to acknowledge the valuable contributions by Prof Gert Saayman who as the Head of Department of Forensic Medicine, University of Pretoria initiated this research, as well as the two psychiatrists who were part of the initial research team before moving on to new ventures, Dr Ilse Plessis and Prof Paul de Wet.

This research was supported by the Phyllis Knocker / Bradlow Award from the Colleges of Medicine of South Africa

We applied the FLAE approach for the sequence of authors.

\section{References}

American Psychiatric Association. (2013). Diagnostic and statistical manual of mental disorders (5th ed.). Arlington, VA: American Psychiatric Publishing.

Bell, C. C., Dominica, F., \& McBride, F. (2010). Commentary: Homicide-suicide in older adults - cultural and contextual perspectives. Journal of the American Academy of Psychiatry and the Law, 38, 312-317. Retrieved from http://jaapl.org/content/38/3/312.long.

Bossarte, R., Simon T., \& Barker L. (2006). Characteristics of homicide followed by suicide incidents in multiple states, 2003-2004. Injury Prevention, 12, 330-8. 
Botello, T. E., Weinberger, L. A., \& Gross, B. H. (2003). Psychological autopsy. In R. Rosner (2nd ed.), Principles and Practice of Forensic Psychiatry (pp. 89-94). Boca Raton FL. CRC Press.

Chan, C., Beh, S., \& Broadhurst, R. (2003). Homicide-suicide in Hong Kong, 19891998. Forensic Science International, 137(2-3), 165-171. doi:10.1016/s0379 0738(03)00350-5.

Cleave, C. (2008). The Other Hand. London, England: Hodder \& Soughton.

Cohen, D., Llorente, M., \& Eisdorfer, C. (1998). Homicide-suicide in older persons. The American Journal of Psychiatry, 155, 390-396. doi: 10.1176/ajp.155.3.390.

Coid, J. (1983). The epidemiology of abnormal homicide and murder followed by suicide. Psychological Medicine, 13, 855-860. doi: 10.1017/S0033291700051576.

Conner, K. R., Beautrais, A. L., Brent D. A., Conwell, Y., Phillips, M. R., \& Schneider, B. (2011). The next generation of psychological autopsy studies. Part I Interview consent. Suicide and Life-Threatening Behavior, 41(6), 594-613.

Cummings, J. L. (1985). Organic delusions: Phenomenology, anatomical correlations and review. British Journal of Psychiatry, 146, 184-197.

Domestic Violence Act 116 of 1998. Government Gazette Vol. 402. No. 19537. Cape Town. Retrieved from https://www.gov.za/sites/www.gov.za/files/a116-98_0.pdf.

Eliason, S. (2009). Murder-suicide: A review of the recent literature. Journal of the American Academy of Psychiatry and the Law, 37, 371-376. Retrieved from http://jaapl.org/content/37/3/371.long.

Enoch, M. D., \& Trethowan, W. H. (1979). Uncommon Psychiatric Syndromes (2nd ed.). Bristol, England: John Wright and Sons.

Felthous, A. R., \& Hempel, A. (1995). Combined homicide-suicides: a review. Journal of Forensic Sciences, 40, 846-57. doi: 10.1520/JFS15396J. 
Flynn, S., Gask, L., Appleby, L., \& Shaw, J. (2016). Homicide-suicide and the role of mental disorder: a national consecutive case series. Social Psychiatry and Psychiatric Epidemiology, 51, 877-884. doi: 10/1007/s00127-016-1209-4.

Goranson, A., Boehnlein, J., \& Drummond, D. (2012). Commentary: A homicide-suicide assessment model. Journal of the American Academy of Psychiatry and the Law, 40, 472-475. Retrived from http://jaapl.org/content/40/4/472.long.

Govender, D. (2015). Is domestic violence being policed in South Africa?. Acta Crim: SAJ of Criminology. 28(2), 32-46. Retrieved from https://hdl.handle.net/10520/EJC185959.

Jena, S., Mountany, L., \& Muller, A. (2009). A demographic study of homicide-suicide in the Pretoria region over a 5 year period. Journal of Forensic and Legal Medicine, 16, 261-265. doi: 10.1016/j.jflm.2008.12.009.

Knoll, J. L. (2016). Understanding homicide-suicide. Psychiatric Clinics of North America, 39(4), 633-647. doi: http://dx.doi.org/10.1016?j.psc.2016.07.009.

Knoll, J. L., \& Hatters-Friedman, S. (2015). The homicide-suicide phenomenon: Findings of psychological autopsies. Journal of Forensic Science, 60, 1253-1257. doi: 10.1111/1556-4029.12819.

Large, M., Smith, G., \& Nielsen, O. (2009). The epidemiology of homicide followed by suicide: A systematic and quantitative review. Suicide and Life-Threatening Behavior, 39, 294-306.

Lecomte, D., \& Fornes, P. (1998). Homicide followed by suicide: Paris and its suburbs, 1991-1996. Journal of Forensic Science, 43, 760-4. doi: 10.1177/1088767907306993.

Leong, G. B., Silva, J. A., Garza-Treviňo, E. S., Olivia, D., Ferrari, M. M., Komanduri, R. V., \& Cadwell J. C. B. (1994). The dangerousness of persons with Othello Syndrome. Journal of Forensic Sciences, 39(6), 1445-1454.

Liem, M. (2010). Homicide followed by suicide: A review. Aggression and Violent 
Behavior, 15, 153-161. doi: 10.1016/j.avb.2009.10.001.

Liem, M., Barder, C., Markwalder, N., Killias, M., \& Nieuwbeerta, P. (2011). Homicidesuicide and other violent deaths: An international comparison. Forensic Science International, 207, 70-76. doi: 10.1016/j.forsciint.2010.09.003.

Malphurs, J. E., Eisdorfer, C., \& Cohen, D. (2001). A comparison of antecedents of homicide-suicide and suicide in older married men. The American Journal of Geriatric Psychiatry, 9, 49-57. doi: 10.1097/00019442-200102000-00008.

Marzuk, P. M., Tardif, K., \& Hirsch, C. S. (1992). The epidemiology of murder-suicide. JAMA, 267, 3179-3183. doi: 10.1001/jama.1992.03480230071031.

Milroy, C. M., Dratsas, M., \& Ranson, D. L. (1997). Homicide-suicide in Victoria, Australia. The American Journal of Forensic Medicine and Pathology, 18, 369-373. doi: 10.1097/00000433-199712000-00011.

Mulder, R., Newton-Howes, G., \& Coid, J. W. (2016). The futility of risk prediction in psychiatry. The British Journal of Psychiatry, 209, 271-272. doi: 10.1192/bjp.bp.116.184960.

Olivier, L., De Jongh van Arkel, J. T., Marchetti M. C., Roos, J. L., Schurink, E. M., Schurink, W. L., \& Visser, M. J. (1991). The phenomenon of family murder in South Africa: An exploratory study. (1st ed). Pretoria SA. HSRC Press.

Roberts, K., Wassenaar, D., Canetto, S. S., \& Pillay, A. (2009). Homicide-suicide in Durban, South Africa. Journal of Interpersonal Violence, 25(5), 877-899. doi: $10.1177 / 0886260509336964$.

Roma, P., Pazzelli, F., Pompili, M., Lester, D., Girardi, P., \& Ferracuti, S. (2012). Mental illness in homicide-suicide: A review. Journal of the American Academy of Psychiatry and the Law, 40, 462-468. http://jaapl.org/content/40/4/462.long.

Roos, J. L., Beyers, D., \& Visser, M. J. (1992). Family murder: Psychiatric and psychological 
causes. Geneeskunde, 34, 25-30.

Roos, J. L., \& Bodemer, W. (1989). Psychiatric aspects of family murder. South African Medical Journal, 75, 121-123.

Rosenbaum, M. (1990). The role of depression in couples involved in murder-suicide and homicide. The American Journal of Psychiatry, 147, 1036-1039. doi: doi.org/10.1176/ajp.147.8.1036.

Rosenbaum, M., \& Bennett, B. (1986). Homicide and depression. The American Journal of Psychiatry, 143, 367-370. doi: http://dx.doi.org/10.1176/ajp.143.3.367.

Saint-Martin, P., Bouyssy, M., \& O'Byrne, P. (2008). Homicide-suicide in Tours, France (2000-2005) - description of 10 cases and a review of the literature. Journal of Forensic and Legal Medicine, 15, 104-109. doi: 10.1016/j.jflm.2007.03.006.

Saleva, O., Putkonen, H., Kiviruusu, O., \& Lönnqvist, J. (2006). Homicide-suicide: An event hard to prevent and separate from homicide or suicide. Forensic Science International, 166, 204-208. doi: 10.1016/j.forsciint.2006.05.032.

Satoh, F., \& Osawa, M. (2016). Trend of homicide-suicide in Kanagawa Prefecture (Japan): Comparison with western countries. Medicine, Science and the Law, 56, 258263. doi: $10.1177 / 0025802416668769$.

Schurink, W. J., De Jongh van Arkel, J. T., \& Roos, J. L. (1992). Methodological account of the execution of qualitative methods in the family murder study. Geneeskunde, 34(8), $13-24$.

Scott, C. L., Swartz, E., \& Warburton, D. O. (2006). The psychological autopsy: Solving the mysteries of death. Psychiatric Clinics of North America, 29, 805-822. doi: 10.1016/j.psc.2006.04.003.

Shepherd, M. (1961). Morbid jealousy: Some clinical and social aspects of a psychiatric symptom. Journal of Mental Science, 107, 687-704.

Shiferaw, K., Burkhardt, S., Lardi, C., Mangin, P., \& La Harpe, R. (2010). A half-century 
retrospective study of homicide-suicide in Geneva - Switzerland: 1956 - 2005. Journal of Forensic and Legal Medicine, 17, 62-66. doi: 10/1016/j.jfml.2009.09.003.

Shneidman, E. S. (1969). Suicide, lethality and the psychological autopsy. International Psychiatric Clinics, 6, 225-250.

Shneidman, E. S. (1981). The psychological autopsy. Suicide and Life-Threatening Behavior, $11,325-340$.

Shrestha, K., Rees, D. W., Rix, K. J. B., Hore, B. D., \& Faragher, E. G. (1985). Sexual jealousy in alcoholics. Acta Psychiatrica Scandinavica, 72, 283-290.

Sibisi, S. (2016). Understanding certain provisions of the Domestic Violence Act: A practitioner's perspective. De Rebus. 563. Retrieved from http://www.derebus.org.za/wp-content/uploads/2016/04/DR_May_2016.pdf.

Sussman, P., \& Kotzé, C. (2013). Psychiatric features in perpetrators of homicide unsuccessful-suicide at Weskoppies Hospital in a 5-year period. South African Journal of Psychiatry, 19, 15-18. doi: 10.7196/SAJP.384.

Todd, J., \& Dewhurst, K. (1955). The Othello Syndrome: A study in the psychopathology of sexual jealousy. Journal of Nervous and Mental Disease, 122(4), 367-374.

Vetten, L. (2017). Police accountability and the Comestic Violence Act 1998. SA Crime Quarterly. 59. 7-18. doi:10.17159/2413-3108/2017/v0n59a1690. 